\title{
疫情期间高校网络课程在线考核的探索与实践—以土木类网络 专业课程为例
}

\author{
范婷 石涓力
}

四川大学锦城学院

DOI:10.32629/er.v3i6.2867

[摘 要] 在线考核是对学生学习网络课程知识和技术掌握情况的评价方式,也是评估其教学效果的重要依据。本文在论述在线考核的必要 性和重要性的基础上, 以土木类网络专业课程的在线考核为例, 建议采用过程性考核和终结性考核相结合的方式, 对学生进行全过程的监督 和考核。

[关键词] 网络课程; 在线考核; 过程性考核; 终结性考核

\section{1 网络课程在线考核的必要性}

今年新型冠状病毒在全球肆虐, 在给我们平静而有序的生活带来了极 大转变的同时, 也打乱了我们新学期的教学秩序, 我们的教学迎来了前所 未有的机遇和挑战。本着教育部门“停课不停学, 停课不停教, 停课不停管” 的总体思想, 各大高校都提早开始准备开学事宜, 纷纷展开网络在线课程 教学。

老师们在解决了平台问题的基础上, 熟练地使用各种慕课平台和各类 直播平台开始网络教学。网络教学打破了传统教学的时间限制和空间限制, 并且采用复合的互动形式, 使得师生们迅速地适应了这种教学方式, 网络 教学取得了很好的效果。

教学先行, 考核并进。作为检验高校教学质量的重要依据, 我们的网络 课程考核改革也迫在眉睫。

\section{2 网络课程在线考核的重要性}

“课程考核是教学管理的重要环节之一, 是检验教学质量和教学水平 的重要手段, 也是考核学生对所学知识掌握程度的重要方式。”网络课程在 线考核同样如此, 它是对学生学习网络课程知识和技术掌握情况的评价方 式, 也是评估网络课程教学效果的重要依据, 在线考核将在一定程度上体 现教师们网络教学的质量。同时, 网络课程在线考核也实时考验了网络课 程的教学管理水平, 在线考核也是我们的网络课程教学管理过程中的各项 工作的协调和完成的重要参考。

3 网络课程在线考核如何实施一以土木类网络专业课程为例

3. 1 网络专业课程在线考核方式

为了更好的达到土木类网络专业课程的教学目标, 完成教学任务, 保证教学质量, 我们对我院土木类网络专业课程的考核方式进行了一 些改进。我们主要采用过程性考核和终结性考核相结合的方式进行, 既注重学生的平时成绩, 又重视期末成绩, 两手并抓, 齐头并进, 对我 们的学生进行全过程的监督和考核, 提高学生参与网络专业课程教学 活动的积极性, 促进学生切实掌握课程知识和提升学习能力, 促进学
生发展。

3.2 网络专业课程在线过程性考核

网络专业课程的在线过程性考核是网络专业课程教学过程管理和教 学质量监控的重要环节, 是促进学生网络专业课程学习、检查网络专业课 程教学效果和保证网络专业课程教学质量的重要手段。抓好网络专业课程 过程性考核的各个环节管理, 不仅能促进学生主动学习, 挖掘学生潜能, 还 能辅助教师检验网络专业课程教学的效果, 改善课程设计, 完善网络专业 课程教学, 实现网络专业课程的教学目标。

为了严格网络专业课程的教学过程管理, 加强对学生学习网络专业课 程的过程考核, 把控学生对网络专业课程知识的掌握情况, 衡量学生网络 专业课程的学习状态, 加大过程性考核比重尤为重要, 网络专业课程的过 程性考核占总考核成绩的 $50 \%$ 较为适宜。

我们制定了科学的过程性考核成绩管理制度, 建立规范的过程性考核 体系, 内容包括网络课程学生考勤、课外作业、阶段测验、课程论文 (设计)、 网络课程课堂表现五个项目, 其中网络课程课堂表现包括在线课程课堂笔 记、回答问题、课堂讨论、在线课程课堂纪律等。

五大过程性考核项目应按照相应的比例进行评定, 任课教师应制定相 应的评定依据与标准, 写入课程教学大纲, 并在网络课程初期向学生公布; 要客观、公平、公正、真实、准确, 应有一定的区分度; 认真、及时、全 面地记载学生的在线过程性考核的成绩; 定期通过网络课程在线向学生公 布在线过程性考核的成绩, 对考核差较的学生予以警示。

3. 3 网络专业课程在线终结性考核

本着在网络专业课程在线终结性考核中考察学生网络学习的质量, 考察学生对网络课程知识的结构认知, 引导和培养学生发现问题、分析 问题、解决问题的能力, 在网络专业课程学习背景下激发学生的创新思 维和创造能力, 鼓励拓宽学生知识广度, 我们在网络专业课程结束后必 须进行网络专业课程的在线终结性考核, 对学生的网络专业课程的学习 效果进行客观评价。

3. 4网络专业课程在线考核方式细化表

\begin{tabular}{|c|c|c|c|c|c|}
\hline \multicolumn{6}{|c|}{ 网络专业课程在线考核 $100 \%$} \\
\hline \multicolumn{5}{|c|}{ 在线过程性考核50\% } & 在线终结性考核 $50 \%$ \\
\hline 网络课程学生考勤20\%课外作业20\% & 阶段测验30\% & 课程论文（设计） $30 \%$ & & 呈课堂表现 (加分顶) & \\
\hline & & & 课堂笔记 & 回答问题 课堂讨论 课堂纪律 & \\
\hline
\end{tabular}


在线终结性考核命题质量不仅决定考试质量, 还关系到考风和考 纪, 影响学风。考核命题应减少客观题与能直接从教材等资料中找到答 案的题目总分值, 可以考虑不定项选择题的形式; 增加非标准答案题目, 同时确保要有来自参考资料的题目; 土木类制图课程题型可以直接采 用绘图题, 力学课程可直接采用计算题, 管理类课程可直接采用案例分 析题等等。

3. 5 传统专业课程终结性考核与网络专业课程终在线结性考核对比分析

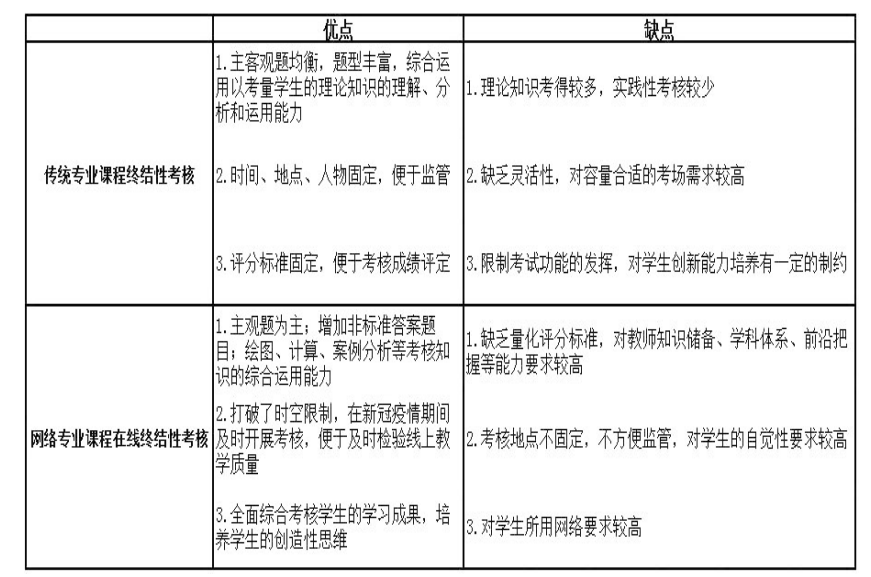

\section{4 今后仍需努力和改进的方向}

充分利用网络平台展开网络专业课程的在线考核, 同时采用在线过程 性考核+在线终结性考核综合考察学生学习网络专业课程的效果, 也极大 地调动了教师工作的积极性, 促进网络专业课程的稳定快速发展。然而在 组织大规模的网络专业课程在线考核过程中, 我们仍有需要继续努力和改 进的地方:

(1) 提高师生对网络课程在线考核的重视。学生应严肃对待网络课程 的学习, 端正在线考核的态度, 养成系统性学习的理念并主动配合教师培 养自身发现问题、分析问题、解决问题的能力。教师应提高自身业务水平、 职业责任感及使命感, 重视在线考核的质量, 持续优化在线考核。

(2) 加强在线考核的监管, 提高学生的学习和考核的自觉性。如何激发
学生的内在学习动力, 培养学生良好的学习习惯, 积极主动地检验自己的 学习效果, 从 “要我学” 向 “我要学转变”, 这将成为教师和教学管理者未 来思考的重点。

\section{[参考文献]}

[1]杨丹宇.应用型人才培养视域下高校文科考试模式改革 [J].湛江师 范学院学报,2014,35(02):36-39.

[2]张蕾.关于高校考核方式改革的思考[J].中外企业家,2020,(16):203.

[3]谢敏, 唐孝蓉. 国内外民办高校课程考核方式对比研究 [J]. 创新教 育,2020,(12):99.

[4] 陈燕. 民办高校课程考核方式改革 [J]. 西部素质教 育,2020,6(04):154-155.

[5]李常杰.普通高校大学物理课程教学与考核模式探讨[J].科教导刊 (下旬),2020,(02):136-137.

[6]王洪丽.试析应用型本科高校课程考核模式的改革措施[J].科技资 讯,2019,17(23):109-110.

[7]杨超.应用型本科高校课程考核模式探索与研究[J].科学大众(科学 教育),2019,(12):163.

[8]张德岁,朱奸,蒋宗霞.应用型本科高校现代汉语课程考核改革研究 [J].常熟理工学院学报,2020,34(01):118-120+124.

[9]胡潇月。应用型高校课程考核改革探究 [J]. 科技经济导 刊,2020,28(11):111-112.

[10]济中,任否, 梁燕秋, 等.中国高校课程考核改革研究[J].教育教学论 坛,2020,(15):122-123.

[11] 赵婧如. 高校课程考核改革探索与实践 [J]. 教育现代 化,2018,5(09):91-92+97.

\section{作者简介:}

范婷 (1986--), 女, 汉族, 四川成都人, 汉语言文字学硕士, 讲师, 研究 方向: 汉语言文字学。

石涓力 (1982--), 女, 汉族, 山东人, 管理学硕士, 助理研究员, 研究方 向: 行政管理。 